J. Dairy Sci. 95:4961-4967

http://dx.doi.org/10.3168/jds.2011-5169

(C) American Dairy Science Association ${ }^{\circledR}, 2012$.

\title{
The welfare of dairy cows is improved in relation to cleanliness and integument alterations on the hocks and lameness when sand is used as stall surface
}

\author{
S. N. Andreasen ${ }^{1}$ and B. Forkman \\ Department of Large Animal Sciences, University of Copenhagen, DK-1870 Frederiksberg C, Denmark
}

\begin{abstract}
Lying down is a highly prioritized behavior in dairy cattle, and previous studies have shown that the type of stall surface has a great effect on the health and welfare of the cow. The objective of this study was to examine the effect of stall surface (rubber mats, mattresses, or sand) on cleanliness, integument alterations on the hocks, lameness, and milk yield of loosely housed dairy cows. Thirty-seven Danish dairy farms with Danish Holstein-Friesian cows were included in the study, and 2,593 cows were examined. Twelve of the farms used rubber mats, 17 of the farms used mattresses, and 8 used sand as the stall surface. Cows housed in facilities with sand in the freestalls were at lower risk of being dirty, had fewer integument alterations on the hocks (e.g., hairless patches, lesions, and swellings), and were less likely to be lame. The cows in facilities with sand in the freestalls also had a significantly higher milk yield compared with cows housed in facilities with mattresses. No differences in milk yield were found between cows housed in facilities with mattresses and rubber mats. Cleanliness, integument alterations, lameness, and milk yield are important indicators of cow welfare; this study showed that, compared with other stall surfaces, sand had a positive effect on these indicators. We therefore conclude that the use of sand as a stall surface is associated with improved welfare.
\end{abstract}

Key words: dairy cow, welfare, stall surface, integument alteration

\section{INTRODUCTION}

The resting area is one of the most important areas in a cow facility. Lying down is a basic requirement, and repeated deprivation of lying down is aversive to cows (Munksgaard and Simonsen, 1996). If a cow is deprived of the opportunity to lie down, it shows signs of stress. A dairy cow prefers to lie down for approximately 12

Received November 22, 2011.

Accepted May 7, 2012.

${ }^{1}$ Corresponding author: sinen@life.ku.dk $\mathrm{h} / \mathrm{d}$, with pregnant cows lying even more. During this period, the time is used to rest, socially interact, and ruminate (Metz, 1984-1985; Phillips, 1993; Cook et al., 2004).

Facilities with freestalls for housing dairy cows were invented and introduced in the United Kingdom in the late 1950s (Rural Design and Building Association, 2009) and introduced into the United States shortly thereafter (Albright, 1964). The underlying thought was to give the cows more space to perform natural behaviors and provide more comfort for the cows.

Facilities with freestalls have evolved since then, particularly regarding the choice of stall surfaces. Many different materials may be used, the most common being rubber mats and mattresses. Apart from these, sand, waterbeds, latex mattresses, straw mattresses, and other materials are used for the stall surface. The stall surface should provide the cow with a clean, dry, and comfortable place for resting. It is also important that the stall surface allow the cow to rise and lie down safely without the risk of slipping (Bickert, 2000).

Cows show clear preferences for different types of stall surfaces. When given a choice between concrete and a softer material (e.g., rubber mats, mattresses, sand, or straw), the cow prefers to lie down on the softer material (Natzke et al., 1982; Herlin, 1997; Norring et al., 2010). When sand is introduced as a stall surface, it is not initially the first choice of the cow and is indeed sometimes not preferred over the concrete of the alleyway (Manninen et al., 2002). However, after a longer adaptation to sand, the cows often prefer it to rubber mats, mattresses, and concrete (Tucker et al., 2003; Wagner-Storch et al., 2003; Thoreson et al., 2006).

Stall surface can affect the cow. Several studies have indicated that animals housed in facilities with sand-bedded freestalls show fewer and less severe hock lesions; that is, hairless patches and wounds (Weary and Taszkun, 2000; Vokey et al., 2001; Lombard et al., 2010), and they are cleaner compared with animals housed in facilities where rubber mats, mattresses, and straw are used as stall surface (Norring et al., 2008). 
Lameness is often described as one of the most important welfare problems and one of the most severe problems in dairy production, for reasons that include pain and adverse effects on milk yield and reproduction (Hernandez et al., 2005). Studies have reported that when comparing prevalence and severity of lameness, sand is associated with a lower incidence of lameness than other stall surfaces (Cook, 2003; Cook et al., 2004; Espejo et al., 2006).

Sand has a loose texture that allows it to give way for pressure and thereby support the cow when it is lying, it conducts heat well, and it drains fast (Stowell and Inglis, 2000). A disadvantage of using sand is that adding fresh sand and replacing all of the sand can be labor intensive and wears down the stall material faster than the other types of stall surfaces. Moreover, handling the manure sand may cause damage to the manureremoving machinery. Also, damage can be inflicted on the milking systems. (Stowell and Inglis, 2000).

The increasing attention toward animal welfare has resulted in the formation of many different welfare assessment protocols, such as the newly developed European Welfare Quality protocols and Animal Needs Index, both of which include many different welfare indicators. For cattle cleanliness, integument alterations, lameness, and milk yield recur as important factors contributing to the welfare of the cow or indicating its general condition (Bartussek et al., 2000; RSPCA, 2008; Welfare Quality, 2009). The data in this study were collected according to the validated European Welfare Quality protocol for dairy cattle. It includes 29 measures, most of which are animal based. The measures may be summed into 12 criteria that can be transformed into 4 principles, which in turn can be recalculated into one overall score representing the general state of welfare on the farm (Welfare Quality, 2009).

The main objective of this study was to evaluate if type of stall surface - rubber mats, mattresses, and deep-bedded sand-affects cleanliness, integument alterations on the hocks, lameness, and milk yield in loose-housed Danish Holstein-Friesian cows. As a crude indicator of aversion to the stall surface, the number of animals lying outside the freestalls was noted.

\section{MATERIALS AND METHODS}

Data were collected as part of a larger observational study that was carried out during the fall and winter of 2010 to 2011 in Denmark.

\section{Study Herds}

Farms included in this study were selected using the following criteria: herd size $>50$ cows per farm,
Danish Holstein-Friesian breed, and use of freestalls. Sixty-three farmers were invited to participate, and 44 responded positively. Of the 44 farms, 7 used stall surfaces not included in this study; thus, the total number of farms included was 37 . All data were collected by the same observer, who had received the required training for implementing the Welfare Quality protocol.

During data collection, all dairy cows were in the facility. Primiparous, multiparous, and dry cows were included in the study; cows housed in sick pens were not included. All farms used housing facilities with access to a minimum of 1 freestall per cow. Freestall dimensions were approximately the same on all farms: mean length $269 \mathrm{~cm}$ (range: 220-280 cm), and mean width $121 \mathrm{~cm}$ (range: 105-130 cm). Twelve farms used rubber mats (approximately 1 to $1.5 \mathrm{~cm}$ thick) as stall surface, 17 farms used mattresses (textile with filling, approximately 5 to $6 \mathrm{~cm}$ thick), and the remaining 8 farms used deep-bedded sand. See Table 1 for distributions of herd size and stall surface in freestalls. On the farms that used rubber mats or mattresses, the freestalls were scraped once a day and a thin layer of litter (either sawdust or shredded straw) was added. On the farms using sand, the whole bedding was changed approximately once every $6 \mathrm{mo}$, and sand was added approximately every second to fourth week. The floor was slatted (23 farms) or solid (14 farms) and was scraped several times a day either with a stationary mechanical cleaner or by a robot cleaner. Three farms using rubber mats, 6 farms using mattresses, and 3 farms using sand used summer grazing. All visits were conducted between 6 to 29 wk after the last day with access to pasture. Milking systems were parlor milking (23 farms) or automatic milking system (14 farms).

\section{Collection of Data and Description of Variables}

Following a sample size recommendation from the European Welfare Quality protocol, 51 to 91 cows were assessed at each farm, depending on herd size, and each cow was assessed using all indicators (Welfare Quality, 2009). A detailed description of the data is given below.

Cleanliness. The cows were inspected from the side (left or right, randomly chosen) and from behind. The hindquarter, lower hind leg (hock), udder, and teats were inspected to assess cleanliness. A lack of cleanliness was defined as visible contamination with either bedding material or manure. A score of 0 was allocated to clean animals or to those with only minor splashing, whereas contamination with separate or continuous plaques of dirt was scored as 2 (Welfare Quality, 2009). In contrast to the Welfare Quality protocol, the teats were scored separately from the udder in this study, 
Table 1. Distribution of management practices for 37 Danish Holstein-Friesian dairy herds using rubber mats, mattresses, or sand as stall surface in freestalls in 2010/2011

\begin{tabular}{lcccrr}
\hline Stall surface & $\begin{array}{c}\text { Farms, } \\
\text { no. }\end{array}$ & $\begin{array}{c}\text { Cows on farm, } \\
\text { n (range) }\end{array}$ & $\begin{array}{c}\text { Farms with summer } \\
\text { grazing, n (\%) }\end{array}$ & $\begin{array}{c}\text { Farms with solid } \\
\text { floor, n }(\%)\end{array}$ & $\begin{array}{c}\text { Farms with parlor } \\
\text { milking, n }(\%)\end{array}$ \\
\hline Rubber mat & 12 & $158(101-264)$ & $3(25)$ & $3(25)$ & $7(58)$ \\
Mattress & 17 & $205(124-452)$ & $6(35)$ & $5(35)$ & $5(63)$ \\
Sand & 8 & $201(120-330)$ & $3(37)$ & $6(59)$ & $6(75)$ \\
\hline
\end{tabular}

and teats could be scored 0 (clean), 1 (minor splashing), or 2 (dirty).

Integument Alterations on the Hocks. Integument alterations were defined as hairless patches, lesions (damaged skin either in form of a scab or a wound), and swellings. The cows were evaluated from one side, again randomly chosen. The hock was inspected from a distance not exceeding $2 \mathrm{~m}$, and the inner side of the opposite hock was included in the evaluation. Each type of integument alteration on each cow was counted whenever the alteration exceeded $2 \mathrm{~cm}$ in diameter (Welfare Quality, 2009).

Lameness. Cows were encouraged to walk in the aisle area after inspection for cleanliness and integument alterations. It was not possible to evaluate lameness in 20 of the 2,593 cows in the sample (because of space allowance or other cows in the aisle restricted the ability to walk freely), and these cows were therefore excluded from the analysis. Even though some cows were excluded, the validated sample size set by the Welfare Quality protocol was attained on all farms. The cows were assessed from behind and from the side. The following scores were used: $0=$ not lame, the timing of steps and weight-bearing equal on all 4 feet; $1=$ lame, imperfect temporal rhythm in stride creating a limp; and $2=$ severely lame, strong reluctance to bear weight on one limb, or more than one limb affected (Welfare Quality, 2009).

Method of Milking and Milk Yield. For every farm, we noted if the cows were milked in an ordinary parlor or in an automatic milking system. The teats were cleaned before milking to ensure hygienic milking. The level of cleanliness of the teats might therefore vary with the milking method. To evaluate milk yield, the farm's yearly mean production of ECM $(\mathrm{kg} / \mathrm{cow})$ was used.

Summer Grazing. The farmer was asked whether grazing was used and, if so, for how many hours and days. A farm was considered as using summer grazing when the cows spent more than $6 \mathrm{~h} / \mathrm{d}$ grazing for a minimum period of $180 \mathrm{~d}$. None of the cows had been on pasture for 6 wk (at least) before inspection.

Flooring. The flooring of the stalls was inspected, and the type of flooring was described as being either slatted or solid.
Cows Lying Completely or Partly Outside the Freestalls. The facility was divided into 8 to 12 segments depending on the number of animals. The number of animals lying in the alleyway or partly outside the freestall (cows having their hindquarter placed on the edge of the freestall) was counted. This is an indication of the cows' willingness to use the freestalls (Welfare Quality, 2009). Only cows lying completely inside the freestall were recognized as lying correctly.

\section{Statistical Analysis}

The software programs SAS JMP and SAS 9.2 (SAS Institute Inc., Cary, NC) were used to perform the statistical analysis. Multiple logistic regression with backward stepwise elimination and correction for overdispersion of farms was used to evaluate the effect of stall surface on cleanliness, integument alterations on the hocks, and lameness. Other explanatory variables used were type of flooring, milking method, and summer grazing. Also included in the analyses was the interaction between the explanatory variables. A criterion of $5 \%$ significance level was used for risk factors and interactions to stay in the model.

A 2-way ANOVA with random effect of farm was used to explore the effect of stall surface and summer grazing on milk yield. This model was validated with the normal quantile plot, a plot of the residuals against the predicted values for ECM yield, and a plot of the studentized residuals against the predicted values for ECM.

During data collection of integument alterations on the hocks, the number of alterations was counted. For statistical analysis, the alterations were summed to 3 categories with 2 outcomes: hairless patches (yes/no), lesions (yes/no), and swellings (yes/no), thereby making the response variables categorical and binary. Stall surface (rubber mat, mattress, and sand) and summer grazing (yes/no) were used as explanatory variables.

Cleanliness on hindquarter, hock, udder, and teats was recorded. The data retrieved when recording the cleanliness of the teats were summed up into 2 categories: teats receiving score 1 and 2 were noted as dirty and teats receiving score 0 were noted as clean. In this way, the cow was categorized as being either clean or 
not clean in each of the areas inspected. Stall surface and type of flooring were used as explanatory variables, and milking method was used as an additional explanatory variable when looking at cleanliness of teats.

For analyzing lameness, the levels partly lame and severely lame were combined and a cow was then categorized as being lame or not. Stall surface, type of flooring, and summer grazing were used as explanatory variables.

To determine if stall surface and summer grazing had an effect on milk yield, mean milk yield (kg of ECM per cow per year) was used. The data were retrieved from a central register where all farms are registered.

\section{RESULTS}

An effect of farm was incorporated in all models as the goodness-of-fit test showed over-dispersion for every response $(P<0.001)$. After this correction, the goodness-of-fit test suggested the model was valid. All interactions between explanatory variables were tested, and none was found to be significant.

\section{Descriptive Results}

Distribution of herd size, grazing management, floor type, and milking system type for each stall surface type can be seen in Table 1. Three farms using rubber mats, 6 farms using mattresses, and 3 farms using sand used summer grazing. Two types of flooring were represented: slatted floor and solid floor. Three farms using rubber mats, 6 farms using mattresses, and 5 farms using sand had solid flooring. Seven farms using rubber mats, 10 farms using mattresses, and 6 farms using sand had parlor milking.

Two animals were found lying partly or completely outside the freestalls. On a farm using rubber mats as stall surface, 1 animal, a bull, was found lying completely outside the freestall because the dimensions of the freestalls were too small. The other animal found lying incorrectly in the freestall was lying partly outside the freestall (on a farm with sand in the freestalls).

\section{Integument Alterations on the Hocks}

Estimated probabilities of hairless patches and lesions, respectively, were 78 and $37 \%$ for cows on rubber mats, 68 and $32 \%$ for cows on mattresses, and 12 and $3 \%$ for cows on sand. See Table 2 for a summary of results. Analysis showed that stall surface had a significant effect on integument alterations (hairless patches and lesions, $P<0.001$; swellings, $P=0.007$ ).

The odds ratio (OR) for having hairless patches on the hocks was 24.9 (95\% CI: 10 to 68) for farms with rubber mats compared with farms with sand, and the OR for cows on farms with mattresses was 14.9 (95\% CI: 6.7 to 38 ) compared with cows on farms with sand. The OR for having lesions on the hocks was $16.9(95 \%$ CI: 6.1 to 67 ) for farms with rubber mats compared with cows on farms with sand, and the OR for cows

Table 2. Significant explaining variables found to influence the welfare of dairy cattle with regard to integument alterations on the hocks, cleanliness on the hocks and teats, and lameness; the estimated probability of occurrence and the odds ratio between stall surfaces are given

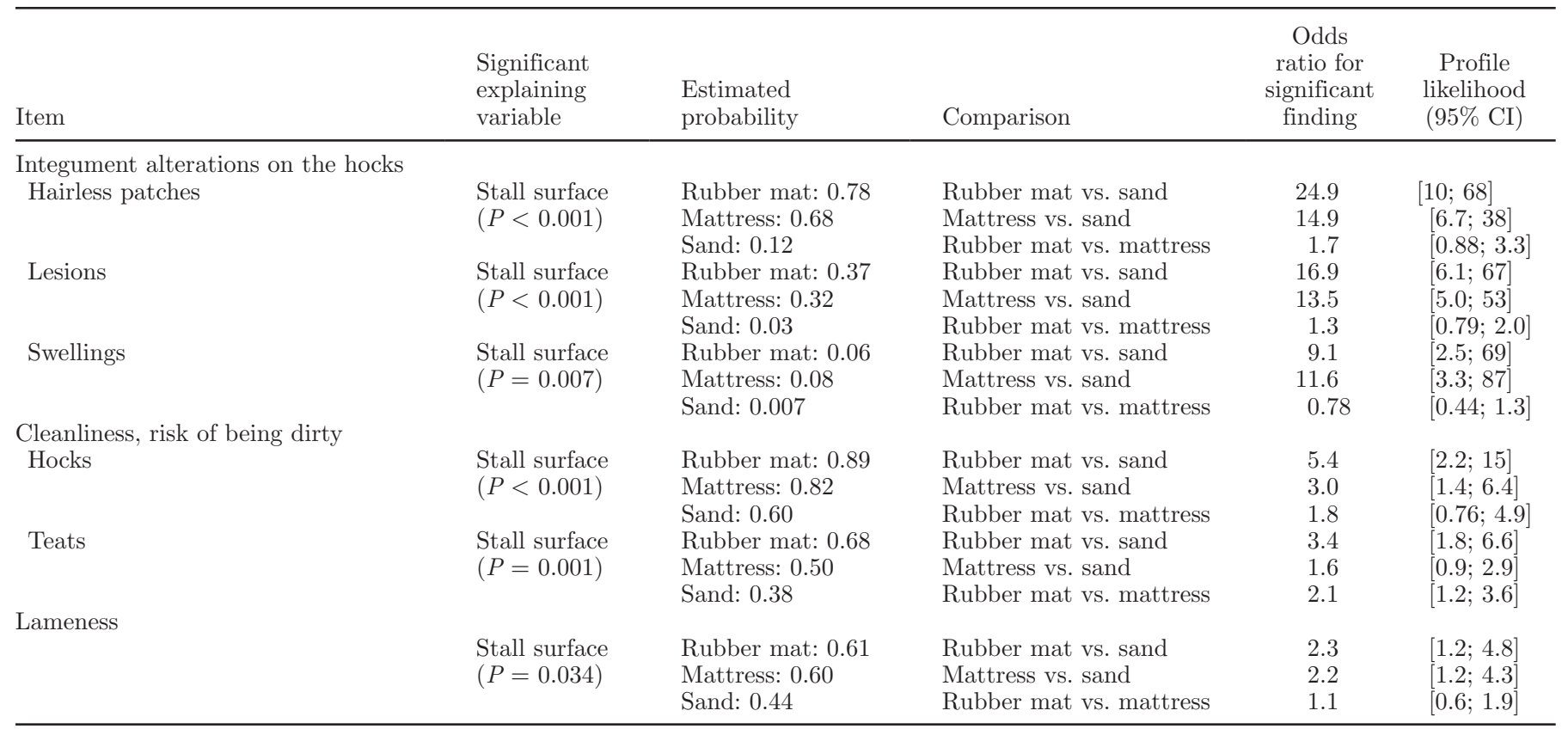


Table 3. Difference in milk yield (kg of ECM) depending on stall surface for 37 Danish Holstein-Friesian dairy herds in freestalls in $2010-2011$

\begin{tabular}{lccc}
\hline Stall surface $(P=0.011)$ & LSM & $95 \%$ CI & Tukey HSD \\
\hline Rubber mat & 10,451 & {$[9,963 ; 10,940]$} & A, B \\
Mattress & 10,039 & {$[9,629 ; 10,450]$} & B \\
Sand & 11,182 & {$[10,583 ; 11,780]$} & A \\
\hline
\end{tabular}

${ }^{1}$ Tukey's honestly significant difference pair-wise comparison. A significant difference is seen when different letters describe the Tukey HSD (i.e., between farms using mattress and sand).

on farms with mattresses was 13.5 (95\% CI: 5 to 53 ) compared with cows on farms with sand. Cows on farms with rubber mats had an OR of 9.1 (95\% CI: 2.5 to 69 ) for having swellings on the hocks compared with cows on farms with sand, and cows on farms with mattresses had an OR of 11.6 (95\% CI: 3.3 to 87) of having swellings on the hocks compared with cows on farms with sand.

\section{Cleanliness}

A significant effect of stall surface was found with regard to cleanliness of the hocks $(P<0.001)$ and teats $(P=0.001)$. For a summary of results, see Table 2 . Cows on farms with rubber mats had an OR of 5.4 (95\% CI: 2.2 to 15) for having dirty hocks compared with cows on farms with sand, and cows on farms with mattresses had an OR of 3.0 (95\% CI: 1.4 to 6.4) of having dirty hocks compared with cows on farms with sand. Cows on farms with rubber mats had an OR of 3.4 (95\% CI: 1.8 to 6.6$)$ for having dirty teats compared with cows on farms with sand.

\section{Lameness}

Estimated probabilities of being lame were $61 \%$ for cows on rubber mats, $60 \%$ for cows on mattresses, and $44 \%$ for cows on sand. For a summary of results, see Table 2. Stall surface was found to have a significant effect on lameness $(P=0.03)$. Cows on farms with rubber mats had an OR of 2.3 (95\% CI: 1.2 to 4.8 ) for being lame compared with cows on farms with sand, and cows on farms with mattresses had an OR of 2.2 (95\% CI: 1.2 to 4.3) for being lame compared with cows on farms with sand.

\section{Milk Yield}

A significant effect of stall surface was found $(P=$ 0.01). The Tukey honestly significant difference test showed that cows on farms that used sand as a stall surface had a significantly higher milk yield than cows on farms that used mattresses as a stall surface. No difference was found between cows on mattresses and cows on rubber mats. For a summary of results, see Table 3.

\section{DISCUSSION}

This study shows that deep-bedded sand as a stall surface is advantageous for the cow and can improve the welfare of the cow compared with rubber mats and mattresses. Cows housed in facilities where sand was used for the stall surface were at significantly lower risk of having hairless patches, lesions, and swellings on the hocks. They were significantly cleaner on the hocks and teats compared with cows on either rubber mats or mattresses. In addition, cows on deep-bedded sand were found to be significantly less lame and they produced more milk. When looking at the number of cows lying incorrectly in the freestalls, we found no indication that cows with sand as stall surface were more reluctant to use the freestalls.

The results of the study agree with many previous studies that have focused on stall surface. These studies also found a significantly positive effect of sand compared with other stall surfaces concerning hock lesions and lameness (Weary and Taszkun, 2000; Espejo et al., 2006; Lombard et al., 2010).

\section{Integument Alterations on the Hocks}

Different risk factors have been found, but integument alterations on the hocks are, to a large degree, affected by the surface on which cows lie (Fulwider et al., 2007; Kielland et al., 2009; Potterton et al., 2011). Alterations of the skin are dynamic and therefore changes in the stall surface or introduction to a new type of stall surface can positively or negatively affect the severity of alterations (Jubb et al., 1993). In this study, changes in the stall surface occurred if the cows were let out on summer grazing. Even though cows could still use the freestalls, most lying would presumably occur in the field when out grazing. Whether or not the cow spent time grazing could therefore have influenced the potential number and severity of integument alterations on the hocks observed in this study. A significant effect of summer grazing was not found in this study; only stall surface was found to have a significant effect, and cows on sand were found to be at lower risk of having hairless patches, lesions, and swellings on the hocks compared with cows lying in freestalls 
with rubber mats and mattresses. A bias in the results could be that a larger proportion of the herds that used sand as bedding also used summer grazing. However, as the herds were visited between 6 and 29 wk after the last day on pasture, we do not expect this to influence the number of integument alterations on the hocks.

\section{Cleanliness}

The cleanliness of a cow depends on many factors. One such factor is how clean and dry the resting area is. The management of the resting areas on farms that used rubber mats and mattresses were alike: they scraped the most posterior part of the resting area once a day and added a thin layer of sawdust or shredded straw. Farms that used sand had no daily routine, but added sand approximately every second to fourth week and changed the whole bedding once every 6 mo. Even though rubber mats and mattresses were scraped daily and were supplied with a thin layer of litter, sand resulted in cleaner cows, most likely because of its absorbing characteristic (Stowell and Inglis, 2000).

An important factor contributing to the overall cleanliness in the facility, and hence the cow, is the flooring and how frequently the floor is scraped (Magnusson et al., 2008). On all study farms, the floors were scraped several times a day, making the type of flooring (solid or slatted) the only factor that differed among the farms. Neither flooring nor its interaction with other explanatory variables was found to have a significant effect on cleanliness.

Access to brushes can also affect cow cleanliness. In particular, cleanliness on the hindquarter can be affected because the cow often uses the brush in this area. In this study, all cows had access to one or more cow-brushes and therefore the effect of brushing was not included in the models.

Both the body of the udder and the teats are affected by the cleanliness and dryness of the stall surface, but teat cleanliness is also affected by the milking procedure. To ensure hygienic milk withdrawal, teats are cleaned before every milking (Elmoslemany et al., 2010); thus, cows returning from the milking parlor or automatic milking system that have not yet resumed lying would have cleaner teats than other cows. This effect was incorporated in the model for cleanliness of teats but did not have a significant effect.

\section{Lameness}

Lameness is a multifactorial disorder (Hernandez et al., 2005; Barker et al., 2010). In this study, stall surface, type of flooring, and summer grazing were used as explanatory factors. Only stall surface was found to have a significant effect on lameness. The positive effect of sand on lameness could be due to the attractiveness of sand as a lying material. Cows that have sand as a stall surface are recumbent for longer periods and have fewer lying bouts than cows on mattresses (Cook et al., 2004; Gomez and Cook, 2010). Sand also has a coarse surface, which prevents the cows from slipping, and the drying effect of sand on the claws may make the environment between the claws less attractive to pathogens. As a bedding material, sand has been proven to induce a lower frequency of hock lesions (Fulwider et al., 2007) and thus a reduced rate of lameness.

Other important factors that can affect lameness are feeding regimen, including additives, and the quality of the feed (Amory et al., 2006). The farms in this study used TMR feeding and the quality was evaluated regularly. The ratio of animals to feeding places can have an effect. On all study farms, a minimum of one feeding place was available per cow, thereby reducing cows pushing each other (Barker et al., 2010). Another important factor affecting lameness is how often a cow is milked and the distance to the milking facility. In this study, milking frequency and distance to the milking facility were not known, and therefore not incorporated. Finally, an important factor affecting gait is the state of the claws (Van der Tol et al., 2004). All study farms performed claw trimming once every $6 \mathrm{mo}$; therefore, this variable was not included.

\section{Milk Yield}

The quantity of milk a cow produces is affected by many factors. Previous studies have shown that a cow in poor general condition has reduced milk yield (Østergaard and Gröhn, 1999; Buckley et al., 2003; Roche et al., 2009). In this study, stall surface was found to affect milk yield. Factors such as breeding, disease control, and culling strategies were not included in the model. Cows housed in facilities using sand as bedding were in better health regarding integument alterations, cleanliness, and lameness, all of which improve the welfare of the cows and thereby increase milk yield.

\section{CONCLUSIONS}

A very important factor in the welfare of dairy cows is the type of stall surface used and, in agreement with previous studies, we found a very positive effect of deep-bedded sand as a stall surface. Animal welfare should be an important aspect of dairy farming, and these results, as well as previous reports, should provide satisfactory scientific background for advising farmers to use sand or a comparable material as a stall surface on their dairy farms. 


\section{ACKNOWLEDGMENTS}

The authors thank the farmers who participated in this study and "R. Nørtoft Thomsens legat" (Copenhagen, Denmark) for supporting the project. We also thank Torben Dahl Nielsen (University of Copenhagen, Department of Large Animal Sciences, Frederiksberg $\mathrm{C}$, Denmark) for reviewing the language in the manuscript.

\section{REFERENCES}

Albright, J. L. 1964. Dairy cattle housing with emphasis on economics, sanitation, health and production. J. Dairy Sci. 47:1273-1281.

Amory, J. R., P. Kloosterman, Z. E. Barker, J. L. Wright, R. W. Blowey, and L. E. Green. 2006. Risk factors for reduced locomotion in dairy cattle on nineteen farms in the Netherlands. J. Dairy Sci. 89:1509-1515.

Barker, Z. E., K. A. Leach, H. R. Whay, N. J. Bell, and D. C. J. Main. 2010. Assessement of lameness prevalence and associated risk factors in dairy herds in England and Wales. J. Dairy Sci. 93:932-941.

Bartussek, H., C. H. Leeb, and S. Held. 2000. Animal needs index for cattle, ANI 35 L/2000 - Cattle. Federal Research Institute for Agriculture in Alpine Regions (BAL) Gumpenstein, Irdning, Austria.

Bickert, W. G. 2000. Milking herd facilities. Pages 27-33 in Dairy Freestall Housing and Equipment. MWPS-7, 7th ed. Iowa State University, Ames.

Buckley, F., K. O. Sullivan, J. F. Mee, R. D. Evans, and P. Dillon. 2003. Relationships among milk yield, body condition, cow weight, and reproduction in spring-calved Holstein-Friesians. J. Dairy Sci. 86:2308-2319.

Cook, N. B. 2003. Prevalence of lameness among dairy cattle in Wisconsin as a function of housing type and stall surface. J. Am. Vet. Med. Assoc. 223:1324-1328.

Cook, N. B., T. B. Bennet, and K. V. Nordlund. 2004. Effect of free stall surface on daily activity patterns in dairy cows with relevance to lameness prevalence. J. Dairy Sci. 87:2912-2922.

Elmoslemany, A. M., G. P. Keefe, I. R. Dohoo, J. J. Wichtel, H. Stryhn, and R. T. Dingwell. 2010. The association between bulk tank milk analysis for raw milk quality and on-farm management practices. Prev. Vet. Med. 95:32-40.

Espejo, L. A., M. I. Endres, and J. A. Salfer. 2006. Prevalence of lameness in high-producing Holstein cows housed in a freestall barn in Minnesota. J. Dairy Sci. 89:3052-3058.

Fulwider, W. K., T. Grandin, D. J. Garrick, T. E. Engle, W. D. Lamm, N. L. Dalsted, and B. E. Rollin. 2007. Influence of free-stall base on tarsal joint lesions and hygiene in dairy cows. J. Dairy Sci. 90:3559-3566.

Gomez, A., and N. B. Cook. 2010. Time budgets of lactating dairy cattle in commercial freestall herds. J. Dairy Sci. 93:5772-5781.

Herlin, A. H. 1997. Comparison of lying area surfaces for dairy cows by preference, hygiene and lying down behaviour. Swed. J. Agric. Res. 27:189-196.

Hernandez, J. A., E. J. Garbarino, J. K. Shearer, C. A. Risco, and W. W. Thatcher. 2005. Comparison of milk yield in dairy cows with different degrees of lameness. J. Am. Vet. Med. Assoc. 227:12921296.

Jubb, K. V. F., P. C. Kennedy, and N. Palmer, ed. 1993. Pathology of Domestic Animals. 4th ed. Elsevier Science Academic Press, Philadelphia, PA.

Kielland, C., L. E. Ruud, A. J. Zanella, and O. Østerås. 2009. Prevalence and risk factors for skin lesions on legs of dairy cattle housed in freestalls in Norway. J. Dairy Sci. 92:5487-5496.
Lombard, J. E., C. B. Tucker, M. A. G. von Keyserlingk, C. A. Kopral, and D. M. Weary. 2010. Associations between cow hygiene, hock injuries and free stall usage on US dairy farms. J. Dairy Sci. 93:4668-4676.

Magnusson, M., A. H. Herlin, and M. Ventorp. 2008. Short communication: Effect of alley floor cleanliness on free-stall and udder hygiene. J. Dairy Sci. 91:3927-3930.

Manninen, E., A. M. de Passillé, J. Rushen, M. Norring, and H. Saloniemi. 2002. Preferences of dairy cows kept in cold loose house for different kind of cubicle flooring. Appl. Anim. Behav. Sci. $75: 281-292$.

Metz, J. H. M. 1984-1985. The reaction of cows to a short-term deprivation of lying. Appl. Anim. Behav. Sci. 13:301-307.

Munksgaard, L., and H. B. Simonsen. 1996. Behavioural and pituitary adrenal-axis responses of dairy cows to social isolation and deprivation of lying down. J. Anim. Sci. 74:769-778.

Natzke, R. P., D. R. Bray, and R. W. Everett. 1982. Cow preference for free stall surface material. J. Dairy Sci. 65:146-153.

Norring, M., E. Manninen, A. M. de Passillé, J. Rushen, L. Munksgaard, and H. Saloniemi. 2008. Effects of sand and straw bedding on the lying behaviour, cleanliness, and hoof and hock injuries of dairy cows. J. Dairy Sci. 91:570-576.

Norring, M., E. Manninen, A. M. de Passillé, J. Rushen, and H. Saloniemi. 2010. Preferences of dairy cows for three stall surface materials with small amounts of bedding. J. Dairy Sci. 93:70-74.

Østergaard, S., and Y. T. Gröhn. 1999. Effects of diseases on test day milk yield and body weight of dairy cows from Danish research herds. J. Dairy Sci. 82:1188-1201.

Phillips, C. J. C. 1993. Resting behaviour. Pages 198-207 in Cattle Behaviour. Farming Press, Ipswich, UK.

Potterton, S. L., M. J. Green, J. Harris, K. M. Millar, H. R. Whay, and J. N. Huxley. 2011. Risk factors associated with hair loss, ulceration, and swelling at the hock in freestall-housed UK dairy herds. J. Dairy Sci. 94:2952-2963.

Roche, J. R., N. C. Friggens, J. K. Kay, M. W. Fisher, K. J. Stafford, and D. P. Berry. 2009. Invited review: Body condition score and its association with dairy cow productivity, health, and welfare. J. Dairy Sci. 92:5769-5801.

RSPCA. 2008. RSPCA welfare standards for dairy cattle. Royal Society for the Prevention of Cruelty to Animals, Horsham, UK.

Rural Design and Building Association. 2009. Cow cubicles-How and where did they originate? Countryside Building 4:32-34.

Stowell, R. R., and S. Inglis. 2000. Sand for bedding. Pages 226-234 in Proc. Dairy Housing and Equipment systems: Managing and planning for profitability. Pub. No. NRAES-129. Plant and Life Sciences Publishing, Ithaca, NY.

Thoreson, D., L. Timms, and D. Lay. 2006. Dairy free stall preference field study. A.S. Leaflet R2100. Animal Industry Report. Iowa State University, Ames.

Tucker, C. B., D. M. Weary, and D. Fraser. 2003. Effects of three types of free-stall surfaces on preferences and stall usage by dairy cows. J. Dairy Sci. 86:521-529.

van der Tol, P. P. J., S. S. van der Beek, J. H. M. Metz, E. N. Nordhuizen-Stassen, W. Back, C. R. Braam, and W. A. Weijs. 2004. The effect of preventive trimming on weight bearing and force balance on the claws of dairy cattle. J. Dairy Sci. 87:1732-1738.

Vokey, F. J., C. L. Guard, H. N. Erb, and D. M. Galton. 2001. Effects of alley and stall surfaces on indices of claw and leg health in dairy cattle housed in free-stall barn. J. Dairy Sci. 84:2686-2699.

Wagner-Storch, A. M., R. W. Palmer, and D. W. Kammel. 2003. Factors affecting stall use for different freestall bases. J. Dairy Sci. $86: 2253-2266$.

Weary, D. M., and I. Taszkun. 2000. Hock lesions and free-stall design. J. Dairy Sci. 83:697-702.

Welfare Quality. 2009. Welfare Quality ${ }^{\circledR}$ Assessment Protocol for Cattle. Welfare Quality ${ }^{\circledR}$ Consortium, Lelystad, the Netherlands. 